\title{
In vitro effectivity of three approved drugs and their synergistic interaction against Leishmania infantum
}

Iman Fathy Abou-El-Naga, Rasha Fadly Mady, Nermine Mogahed Fawzy Hussien Mogahed Medical Parasitology Department, Faculty of Medicine, Alexandria University, Alexandria, Egypt

Introduction: Leishmaniasis remains one of the neglected tropical diseases. Repurposing existing drugs has proven to be successful for treating neglected tropical diseases while combination therapy is a strategic alternative for the treatment of infectious diseases. Auranofin, lopinavir/ritonavir, and sorafenib are FDA approved drugs used in the treatment of diverse diseases by acting on different essential biological enzymes.

Objective: To evaluate the effects of monotherapy and combined therapies with the three drugs against Leishmania infantum.

Materials and methods: We compared the leishmanicidal effects of the three drugs on promastigotes in vitro as regards the parasite count, the drug concentration providing a half-maximal response, and the ultrastructural changes of the parasite. We determined the fractional inhibitory concentration index of combined drugs in two ways, as well as the activity of the three drugs together to establish their synergetic effect.

Results: The monotherapy with the three drugs was effective with auranofin showing the best leishmanicidal effect $\left(E_{50}=1.5 \mu \mathrm{M}\right)$, whereas sorafinib reduced parasite growth at $\mathrm{EC}_{50}=2.5 \mu \mathrm{M}$. The scanning electron microscopy of promastigotes from all treated media showed distortion in the shape with loss of flagella and bleb formation. Acidocalcinosis was evident by transmission electron microscopy with all treatments suggesting apoptosis. Treatment with lopinavir/ritonavir showed signs of autophagy. The two-way combination of the drugs led to additive interactions while the combination of the three drugs showed synergistic action.

Conclusion: Each drug when used as monotherapy against Leishmania spp. was effective, but the combination therapy was more effective than the individual drugs due to the additive or synergistic effects.

Keywords: Leishmania infantum; drug synergism; apoptosis; autophagy.

Efectividad in vitro de tres fármacos aprobados y su interacción sinérgica contra Leishmania infantum

Introducción. La leishmaniasis sigue siendo una de las enfermedades tropicales desatendidas. La reutilización de medicamentos existentes ha demostrado ser exitosa para tratar enfermedades tropicales desatendidas y la terapia combinada es una alternativa estratégica para el tratamiento de enfermedades infecciosas. Auranofin, lopinavir/ritonavir y sorafenib son medicamentos aprobados por la Food and Drug Administration (FDA) de Estados Unidos utilizados en el tratamiento de diversas enfermedades, pues actúan sobre diferentes enzimas biológicas esenciales.

Objetivo. Evaluar los efectos terapéuticos de la monoterapia y de los tres fármacos combinados contra Leishmania infantum.

Materiales y métodos. Los efectos leishmanicidas de los tres fármacos sobre los promastigotes se compararon in vitro en cuanto al recuento de parásitos, la concentración del fármaco que proporcionara una respuesta semimáxima y los cambios ultraestructurales del parásito. Se calculó el índice de concentración inhibitoria de fracciones de fármacos combinados de dos maneras y la actividad de los tres fármacos juntos para determinar el efecto sinérgico.

Resultados. La monoterapia con los tres medicamentos fue efectiva, pero la auranofina tuvo el mejor efecto antileishmanicida con un $\mathrm{CE}_{50}$ de $1,5 \mu \mathrm{M}$, en tanto que el sorafinib redujo el crecimiento del parásito con un $\mathrm{CE}_{50}$ de $2,5 \mu \mathrm{M}$. La microscopía electrónica de barrido de promastigotes de todos los medios tratados mostró una distorsión en la forma, con pérdida de flagelos y formación de ampollas. La acidocalcinosis fue evidente por microscopía electrónica de transmisión con todos los tratamientos, lo que sugiere apoptosis. El tratamiento con lopinavir/ritonavir mostró signos de autofagia. La combinación de dos medicamentos condujo a interacciones aditivas, mientras que la combinación de las tres drogas produjo una acción sinérgica.

Conclusión. Los tres medicamentos usados como monoterapia contra Leishmania spp. fueron efectivos, pero el tratamiento combinado lo fue en mayor medida debido a los efectos aditivos o sinérgicos.

Palabras clave: Leishmania infantum; sinergismo farmacológico; apoptosis; autofagia. 
Leishmaniasis is one of the neglected tropical diseases. It affects as many as 12 million people living in endemic areas in 98 countries. About 350 million people are considered to be at risk, most of them in developing countries (1-3). Leishmania species cause a wide clinical spectrum that includes cutaneous, mucocutaneous, and visceral leishmaniasis. The most common is the cutaneous form, which causes disfiguring and stigmatizing skin lesions whereas mucocutaneous leishmaniasis is significantly less common. Visceral leishmaniasis is fatal if not treated (4).

Currently, limited choices of drugs are used for the treatment of leishmaniasis. There are no approved vaccines nor prophylactic drugs. Pentavalent antimonial compounds, sodium stibogluconate, pentamidine, various amphotericin B formulations, miltefosine, and paromomycin are the approved medications at the moment. Imiquimod and sitamaquine are under clinical assessment (5). However, the available drugs have limitations which include toxicity, long courses, high costs, undesirable route of administration, teratogenicity, and drug resistance. So far, no safe and effective anti-Leishmania drug is available in the market (6). Recent research funded by various organizations is only directed towards clinical trials and diagnostic studies of leishmaniasis in endemic countries. Consequently, there is still an urgent need to develop new therapeutics for leishmaniasis.

New drug trials are presently aimed at interfering with vital biochemical and metabolic pathways of the parasite and in this rationale, enzymes are the most important focus. The target enzymes in the parasite should have major structural and functional differences from those of the mammalian host to achieve selective inhibition of the target sites (7).

Repurposing existing drugs has proven to be successful for treating neglected tropical diseases. The new uses approved by the US Food and Drug Administration (FDA) are a shortcut between the preclinical testing and clinical trials. This strategy reduces the funds needed for the preclinical researches and the study of the safety profiles and pharmacological characteristics $(8,9)$.

For this study, we chose three FDA-approved drugs, namely auranofin, lopinavir/ritonavir and sorafenib, which act as inhibitors of different protease enzymes to study their effect as monotherapy and combination therapy on Leishmania infantum. Leishmania spp. proteases are very important virulence factors as they are involved in host tissue invasion, survival inside macrophages, and host immune response modulation for which they are considered good targets (10). The efficacy of the drugs was compared to that of amphotericin B, a polyene antibiotic that acts on the membrane sterols of Leishmania spp. promastigotes producing the loss of the permeability barrier to small metabolites (11). Although amphotericin B is widely used in the treatment of leishmaniasis, its toxicity is considerable (12).

Auranofin is a gold-containing drug used in the treatment of rheumatoid arthritis. It emerged as a strong inhibitor of mammalian thioredoxin reductases (13). Recently, the drug showed a remarkable antiparasitic activity by inhibiting those enzymes involved in the control of the reduction/oxidation (redox) process. These enzymes are essential for maintaining intracellular levels of reactive oxygen species. Leishmania and other Trypanosomatids contain trypanothione reductase, a key enzyme of redox metabolism (14). Trypanothione reductase and mammalian glutathione reductase show notable differences in the structure validating specific inhibitors designed against trypanothione reductase as an ideal drug against Leishmania spp. without changing the mammalian glutathione reductase activity (7). 
Lopinavir/ritonavir is a highly active anti-retroviral medication used against HIV (15). The drug is an aspartyl peptidase inhibitor composed of two antiretroviral drugs: lopinavir and ritonavir, in a ratio of 4:1 (16). Peptidases are essential in a wide range of biological functions (17). They are recognized as therapeutic targets for important diseases and many micro-organisms including Leishmania (18-20). These enzymes are classified into five distinct clans (AA, $A C, A D, A E$, and $A F$ ) and 16 families according to the MEROPS database. The classical aspartic peptidases Clan AA is further subdivided into eight families of which family A2 includes the HIV peptidase. In Trypanosomidae, the aspartic peptidases belong to two clans: clan $A A$ and clan $A D(21)$.

Recently, the co-infection of Leishmania spp. and HIV has been increasingly reported in leishmaniasis endemic areas (4). The introduction of the highly active antiretroviral therapy (HAART) has shown a recognizable decrease in Leishmania/HIV co-infection as regards incidence, pathology, and clinical presentation of the disease (22). Experimental studies on different Leishmania species using HIV peptidase inhibitors have enforced the epidemiological results documenting a decrease in the incidence of Leishmania/HIV co-infection after treatment with these drugs (21-25).

Sorafenib is a multi-kinase inhibitor used for the treatment of advanced hepatocellular and renal cell carcinoma. Recently, it was identified as an active agent against $L$. donovani and different species of Leishmania causing cutaneous leishmaniasis (26). A large number of kinases, especially cyclindependent and mitogen-activated kinases, are responsible for cell-cycle control in Leishmania. Although kinases are recognized as targets for many diseases, they have been poorly studied as targets for Leishmania (27). The anti-leishmanial potency of sorafenib is due to the non-specific inhibition of many diverse protein kinases rather than that of the mammalian kinases (28).

Combination therapy is a strategic alternative for the treatment of infectious diseases. It is currently considered as one of the most rational alternatives to increase drug activity, reduce treatment duration and dosage, reduce toxicity, and delay or prevent drug resistance. It has been efficiently used in the treatment of malaria, tuberculosis, and AIDS (29). However, it is uncommon to treat leishmaniasis with combined drugs (30-32), but the need for combination therapy against leishmaniasis has emerged (33).

In this study, we evaluated the anti-leishmanial effect of auranofin, lopinavir/ritonavir and sorafenib against $L$. infantum promastigotes compared to the gold standard drug for leishmaniasis, amphotericin B. The synergistic, additive or antagonistic effects of combined therapy were also investigated, as well as the morphological changes of the parasite treated with the aforementioned drugs at the ultrastructural level.

\section{Materials and methods}

\section{Maintenance of the Leishmania strain}

Leishmania infantum MON1 is the visceral leishmaniasis strain used in this study. It was kindly provided by Professor Jean Dupouy Camet, president of the European Federation of Parasitologists. It was further maintained in the Laboratory of Medical Parasitology Department, Faculty of Medicin at Alexandria University. Leishmania infantum promastigotes were maintained under standard culture conditions in Novey-MacNeal-Nicoll (NNN) media. Parasites were sub-cultured every seven days (34). 


\section{Tested drugs}

Three commercially available FDA-approved drugs were used in this study: auranofin, purchased from Abbott; lopinavir/ritonavir, purchased from Astellas pharma SPA, and sorafenib, purchased from Bayer. Amphotericin B was used as the gold standard.

\section{Determination of the in vitro anti-leishmanial activity}

Ten $\mu \mathrm{M}$ stock solutions were prepared from each drug in $1 \%$ DMSO. The negative control was prepared from the $1 \%$ DMSO and the positive control was $10 \mu \mathrm{M}$ of $\mathrm{AmB}$. We incubated $1 \times 10^{6}$ Leishmania promastigotes suspended in $100 \mu \mathrm{L}$ of culture media for three hours before adding the test drugs. After 48 hours of incubation with each drug preparation at $25^{\circ} \mathrm{C}$, an aliquot of each tube was added to an equal amount of a solution containing $0.2 \%$ formalin to stop parasite movement and facilitate the counting using a Neubauer chamber (35). Auranofin, lopinavir/ritonavir, and sorafenib were tested in ascending concentrations ranging from 0.1 to $20 \mu \mathrm{M}$. Amphotericin $\mathrm{B}$ was tested in a dilution range of 0.01 to $17 \mu \mathrm{M}$.

\section{Determination of the fractional inhibitory concentration index, isobologram construction, and classification of the nature of the interaction}

The fractional inhibitory concentration (FIC) is the one that caused a $50 \%$ decrease in the growth $\left(\mathrm{EC}_{50}\right)$ of promastigotes. It was calculated for each tested drug and each concentration. All tests were performed in triplicate (9).

To test for synergy, drugs were evaluated in quadruplicate individually to determine the $\mathrm{EC}_{25}$; each compound in a pair was required to inhibit $25 \pm 10 \%$ of growth in untreated media.

Drug combinations that showed possible synergism were subjected to formal isobologram analysis using the fixed ratio method (36).

Serial two-fold dilutions were performed in triplicate. We calculated the $\mathrm{EC}_{50}$ for each drug ratio. The fractional inhibitory concentrations were calculated as the following:

$\mathrm{EC}_{50}$ when in combination / $\mathrm{EC}_{50}$ of individual drug

The sum of the FIC was calculated as follows: $\Sigma$ FIC $=$ FIC drug A + FIC drug B. The mean sum of the FIC ( $\bar{X} \Sigma \mathrm{FIC})$ was calculated as the average of SFIC from the three different fixed ratios. The interactions were considered synergistic for $\bar{X} \Sigma \mathrm{FIC} \leq 0.5$, additive for $\bar{X} \Sigma \mathrm{FIC}$ between 0.5 and 4 , and antagonistic for $\bar{X} \Sigma \mathrm{FIC}>4$ (9).

\section{Ultrastructural study}

A scanning electron microscope (SEM) (JEOL-JSM-25 SIITM) and a transmission electron microscope (TEM) (JEOL $100 \mathrm{CX}^{\mathrm{TM}}$ ) were used to examine $L$. infantum promastigotes after their treatment with auranofin, lopinavir/ritonavir, and sorafenib for $48 \mathrm{~h}$ at $26^{\circ} \mathrm{C}$ in comparison to positive and negative controls. The specimens were processed for SEM and TEM $(37,38)$.

\section{Statistical analysis}

All parasite burden data were expressed as the mean \pm standard deviation. Abnormally distributed data were expressed using the median (min-max) and 
compared using the Kruskal Wallis test. Significance between groups was determined using the Mann Whitney test. A p-value of $<0.05$ was considered statistically significant (39).

\section{Results}

\section{In vitro anti-leishmanial activity}

It was clear that all individual drugs, auranofin, lopinavir/ritonavir, sorafenib, and amphotericin B, limited in vitro parasite growth after 48 hours of parasite replication whereas DMSO had no significant effect. Lopinavir/ritonavir reduced parasite growth at $1.7 \mu \mathrm{M}$. As regards to auranofin, the lower drug concentration limiting parasite growth by $50 \%\left(\mathrm{EC}_{50}\right)$ was $1.5 \mu \mathrm{M}$. sorafenib while $\mathrm{AmB}$ showed the highest $\mathrm{EC}_{50}$ concentrations ( $2.5 \mu \mathrm{M}$ and $2 \mu \mathrm{M}$, respectively) (tables 1 and 2 ).

\section{Synergy testing and isobologram analysis}

$\mathrm{EC}_{25}$ values were measured for each of the drugs in every possible combination (table 3 ). Four combinations were tested in formal isobologram analyses to quantify the interactions by this standard method.

\section{Fractional inhibitory concentration}

Sum of FIC for combination A (auranofin + lopinavir/ritonavir) $=1.53+0.45$ $=1.98=$ additive.

Sum of FIC for combination B (sorafenib + lopinavir/ritonavir) $=0.59+0.8$ $=1.39=$ additive.

Sum of FIC for combination C (auranofin + sorafenib $)=1.2+0.48=1.68=$ additive.

Table 1. Effect of different drugs on in vitro proliferation of Leishmania infantum promastigotes

\begin{tabular}{lc}
\hline Drug & $\begin{array}{c}\text { Growth } \\
\text { percentage }\end{array}$ \\
\hline Auranofin (3 mg) & 4.27 \\
Lopinavir/ritonavir (200 mg) & 6.8 \\
Sorafenib (200 mg) & 9.84 \\
Amphotericin B & 11 \\
Auranofin+ lopinavir/ritonavir (combination A) & 3.75 \\
Lopinavir/ritonavir + sorafenib (combination B) & 5.1 \\
Auranofin + sorafenib (combination C) & 8.25 \\
Auranofin + sorafenib+ lopinavir/ritonavir (combination D) & 4.75 \\
\hline
\end{tabular}

Table 2. EC50* of the different drugs

\begin{tabular}{lc}
\hline Drug & $\mathrm{EC}_{50}(\mu \mathrm{M})$ \\
\hline Auranofin $(3 \mathrm{mg})$ & 1.5 \\
Lopinavir/ritonavir $(200 \mathrm{mg})$ & 1.7 \\
Sorafenib $(200 \mathrm{mg})$ & 2.5 \\
Amphotericin B & 2 \\
\hline${ }^{*} \mathrm{EC}_{50}$ values are means of triplicate assays.
\end{tabular}

Table 3. $\mathrm{EC}_{25}{ }^{*}$ of the different drugs in every combination

\begin{tabular}{llll}
\hline Drug & Lopinavir/ritonavir & Auranofin & Sorafenib \\
\hline Auranofin + lopinavir/ritonavir (combination A) & $0.77 \mu \mathrm{M}$ & $2.3 \mu \mathrm{M}$ & \\
Lopinavir/ritonavir + sorafenib (combination B) & $1 \mu \mathrm{M}$ & & $2 \mu \mathrm{M}$ \\
Auranofin + sorafenib (combination C) & & $1.8 \mu \mathrm{M}$ & $1.2 \mu \mathrm{M}$ \\
Auranofin + sorafenib + lopinavir/ritonavir (combination D) & $0.3 \mu \mathrm{M}$ & $0.3 \mu \mathrm{M}$ & $0.3 \mu \mathrm{M}$ \\
\hline${ }^{*} \mathrm{EC}_{25}$ values are means of triplicate assays. & & &
\end{tabular}


Sum of FIC for combination D (auranofin + lopinavir/ritonavir + sorafenib) $=$ $0.17+0.12+0.2=0.49=$ synergism .

When these results were statistically analyzed, lopinavir/ritonavir showed no significant difference from other drugs either when used alone or in combination. The growth inhibition in auranofin-treated media was significantly greater than that treated with sorafenib and amphotericin B, but no statistically significant difference was found between it and any combination. Despite the reduction in parasite growth, sorafenib was the least potent drug in comparison to auranofin and combinations $\mathrm{B}, \mathrm{C}$, and D.

Combinations $B, C$, and $D$ showed a significant reduction in the growth of promastigotes compared to amphotericin B and combination A (table 4).

\section{Ultrastructural study}

Scanning electron microscopy after 48 hours of the culture of parasites inoculated in fresh media with no drug added showed normal morphology (figure $1 \mathrm{a}$ and $\mathrm{b}$ ). Promastigotes from all treated media showed distortion in the parasite shape with loss of flagella and bleb formation. Auranofintreated promastigotes exhibited severe shape distortion while some showed a rounded form (figure 1c). Irregularities in the cell membrane of the parasite were highly evident in lopinavir/ritonavir-treated promastigotes (figure 1d) while dimple-like structures on the cell surface were observed in sorafenibtreated parasites (figure 1e).

Normal ultrastructure contents were detected using transmission electron microscopy after 48 hours of the culture of parasites inoculated in fresh media with no drug added (figure $2 a$ and $b$ ). Acidocalcinosis was evident in the parasites from all treated media, which suggested apoptosis. Auranofin-treated promastigotes showed evident acidocalcinosis (figure 2c). Lopinavir/ritonavirtreated promastigotes showed very evident acidocalcinosis, degenerated nuclear membrane, and chromatin granules suggesting apoptosis. Vacuoles with different densities and autophagy vesicles with double membrane were also present (figure $2 \mathrm{~d}$ ). Sorafenib-induced apoptosis with shrinkage of the cytoplasm (figure $2 \mathrm{e}$ ) was also evidenced.

Table 4. In vitro activity of different drugs and combinations against promastigotes

\begin{tabular}{lc}
\hline Parasite count in culture media treated with different drugs & Median (min-max) \\
\hline Auranofin (300 mg) & $38(27-77.5)^{\mathrm{b}}$ \\
Lopinavir/ritonavir (200 mg) & $70(18-100)^{\mathrm{ab}}$ \\
Sorafenib (200 mg) & $101(40-150)^{\mathrm{a}}$ \\
Amphotericin B & $107.5(88-137)^{\mathrm{a}}$ \\
Auranofin + lopinavir/ritonavir (combination A) & $37.5(15-60)^{\mathrm{b}}$ \\
Lopinavir/ritonavir+ sorafenib (combination B) & $51(20-82)^{\mathrm{b}}$ \\
Auranofin + sorafenib (combination C) & $82.5(45-120)^{\mathrm{ab}}$ \\
Auranofin + sorafenib + lopinavir/ritonavir (combination D) & $40(20-90)^{\mathrm{b}}$ \\
\hline
\end{tabular}

Abnormally distributed data was expressed using the median (min-max) and compared using the Kruskal Wallis test. Significance between groups was established using the Mann Whitney test.

Different superscripts are statistically significant. 

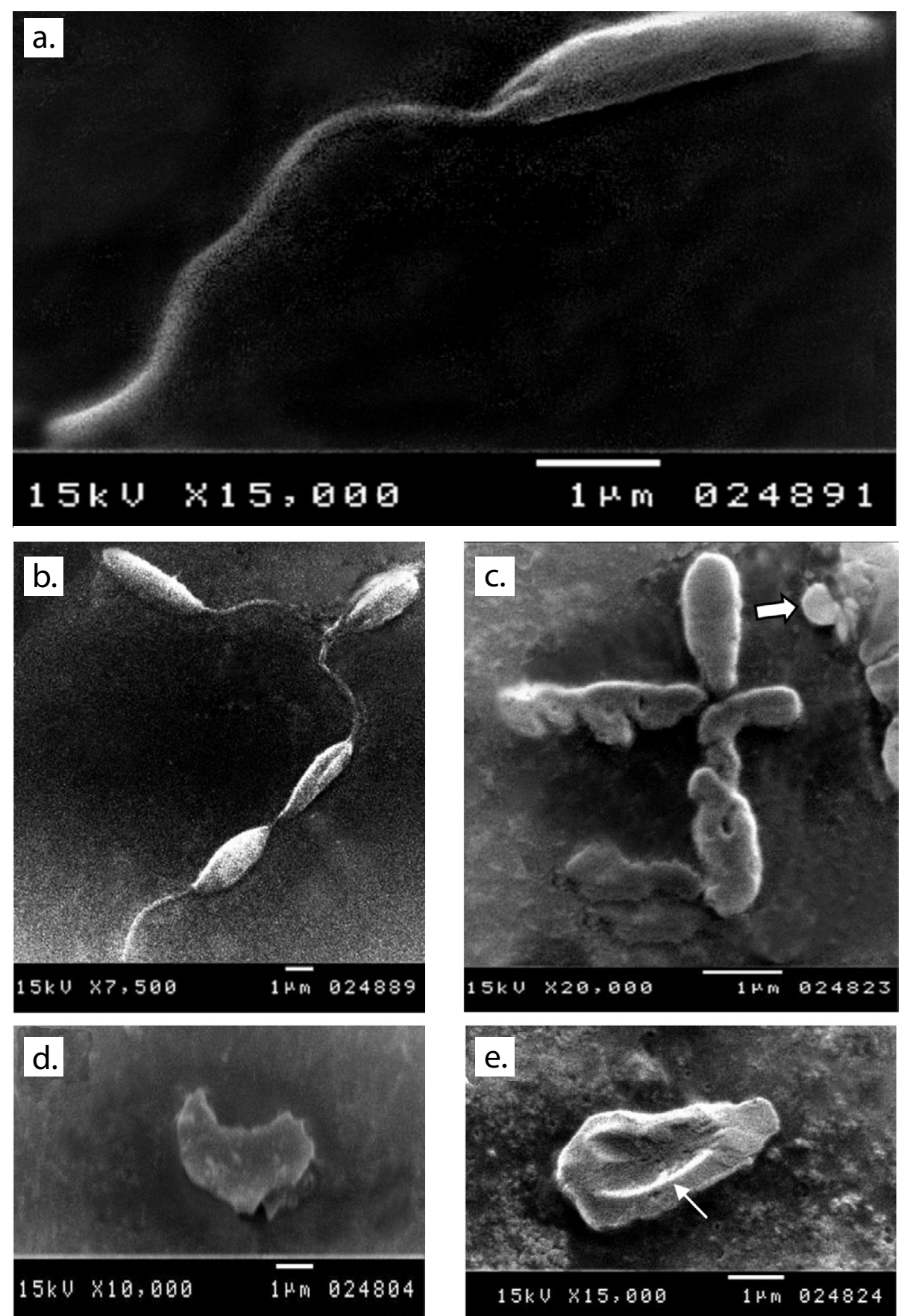

Figure 1. Ultrastructural changes observed in promastigotes from the different media under study. $a$ and b: Normal shape of parasite inoculated in fresh media with no drug added after 48 hours of culture. c: Auranofin-treated parasite showing shape distortion and loss of flagella and some showing a round form (arrow). d: Severe distortion in the shape and loss of flagella with detached membrane in lopinavir/ritonavir-treated promastigote. e: Sorafenib-treated promastigote showing a large dimple (arrow) on its body surface as well as loss of flagella. 

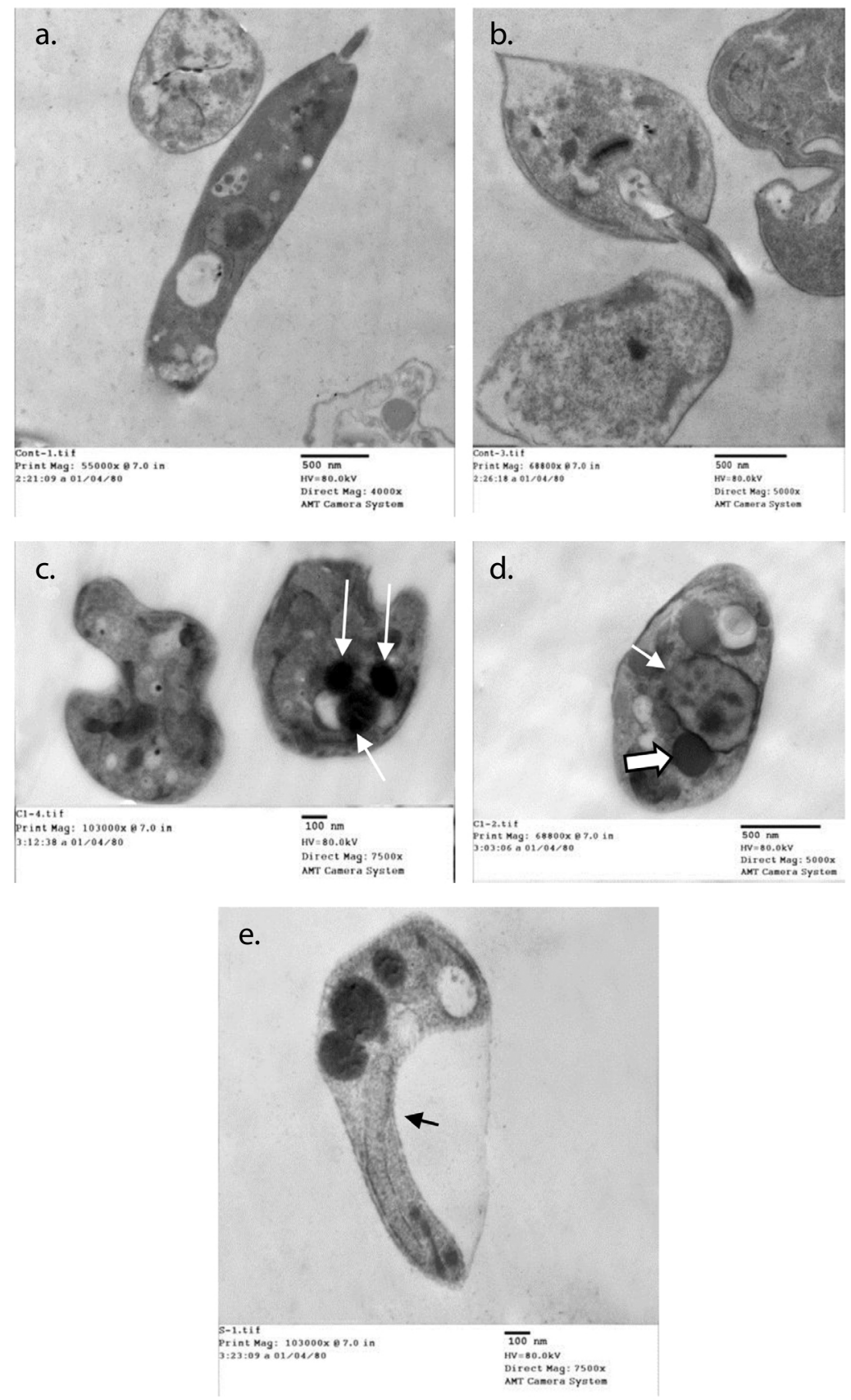

Figure 2. Ultrastructural changes in promastigotes from different media. a and b: Normal parasite inoculated in fresh media with no drug added after 48 hours of culture. c: Auranofin-treated promastigotes showing evident acidocalcinosis (arrows). d: Lopinavir/ritonavir-treated promastigotes showing evident acidocalcinosis (thick arrow) and degenerated nuclear membrane (thin arrow) with condensed chromatin granules close to the nuclear membrane suggesting apoptosis. Vacuoles with different densities and autophagy vesicles with double membrane were also present. e: Sorafenibtreated promastigotes showing acidocalcinosis and shrinkage of the cytoplasm (arrow). 


\section{Discussion}

Despite several trials, there are no effective vaccines against Leishmania spp. at the moment and chemotherapy remains the mainstay for the control of leishmaniasis. The currently used drugs are unsafe, expensive, and lead to resistance (40) while the treatment with protease inhibitors has been tried before in several research studies. Accordingly, in this study, we evaluated the effect of three different commercially available enzyme inhibitors against $L$. infantum. We compared the monotherapy and the combination therapy of auranofin, lopinavir/ ritonavir and sorafenib. The drugs were chosen for their well-known history of safe clinical profile and their inhibition of essential enzymes (41).

Our results showed that auranofin had the most effective anti-leishmanial activity. It is the only drug that when used individually led to a significant inhibition in the parasite count compared to amphotericin B. At $10 \mu \mathrm{M}$, auranofin significantly reduced the parasite count compared to sorafenib but the results were insignificant compared to that of lopinavir/ritonavir. Furthermore, with auranofin, the growth percentage and the $\mathrm{LC}_{50}$ of the parasite were the lowest in comparison to lopinavir/ritonavir, sorafenib, and amphotericin $B$. The effect of auranofin against $L$. infantum is due to the inhibition of trypanothione reductase enzyme, one of the top targets in drug discovery for leishmaniasis, as it protects the parasite from oxidative damage and toxic heavy metals and allows the delivery of the reducing equivalents for DNA synthesis $(14,42)$. Lopinavir/ritonavir was found to have more efficacy than amphotericin B. The proteolytic activity of the HIV protease inhibitors has been demonstrated in other studies of different Leishmania species $(21,24,25,43)$. Alves, et al. (44), explained another way of their action through the modulation of innate defense mechanisms via different cellular pathways. They also showed that, although HIV protease inhibitors are highly efficient to control HIV, they might also influence the course of leishmaniasis in HIVLeishmania-co-infected individuals.

In the present study, sorafenib showed the least leishmanicidal activity among the drugs under study. It did not significantly reduce the promastigotes compared to amphotericin $\mathrm{B}$ and had a higher $\mathrm{LC}_{50}$. The drug is a multikinase inhibitor and was found to be active against $L$. donovani in culture by identifying cycline-dependent and mitogen-activated kinases as targets for anti-leishmanial treatment $(26,27)$. Recently, it was found that sorafenib utilizes a non-apoptotic form of cell death (ferroptosis) on tumor cells. Ferroptosis is a regulated form of cell death resulting from iron-dependent lipid peroxide accumulation as shown by Yu, et al. (45).

Combination therapy with commercially available drugs aims at reducing the costs, toxicity, and duration of the treatment and represents a promising alternative rationale (46). Therefore, we tried the drug combinations of two and three compounds. The results showed that the interactions between the combination of two compounds were additive. More importantly, the combination of three compounds showed a synergetic effect. Although neither lopinavir/ritonavir nor sorafenib used individually resulted in significant inhibition of the parasite when combined the inhibition significant (combination B). Butcher attributed this unexpected result to the combination of two drugs with different biomolecular targets (47). Furthermore, the combination of auranofin and lopinavir/ritonavir (combination A) led to a significant reduction in the parasite count compared to amphotericin B possibly because of the strong anti-leishmanial effect of auranofin added to the different mechanism 
of action exhibit by lopinavir/ritonavir in modulating the immune system. Our findings are supported by Lewis, et al. results in an animal model where a combination of auranofin and an antiretroviral drug was able to reduce significantly post-therapy viremia (48).

The use of drugs with synergistic or additive activity in combination therapy delays or prevents the development of resistance and may shorten the treatment, which, in turn, decreases the undesirable effects of each drug $(49,50)$. Moreover, this alternative strategy leads to cost and time reductions (41). The search for synergism by combining approved drugs can rapidly take to preclinical and clinical phases (51).

In an attempt to explore the effect of each drug on the promastigotes, we conducted ultrastructural studies on the treated parasites. SEM of promastigotes treated with auranofin, lopinavir/ritonavir, and sorafenib for 48 hours showed severe shape distortion and loss of flagella with irregularities on the cell surface. Some promastigotes treated with auranofin exhibited a rounded appearance. Sharlow, et al., found the same morphology in $L$. amazonensis promastigotes treated with auranofin (52). Rigobello, et al. (13), and Ilari, et al. (14), attributed this rounded swelling to the inhibition of trypanothione reductase and the membrane permeability transition. This morphological distortion had not been observed with any known leishmanicidal drugs (52).

In our study, TEM images suggested that auranofin, lopinavir/ritonavir, and sorafenib exerted their anti-leishmanial effect on L. infantum promastigotes by inducing apoptosis. There were some changes in the essential organelles including the nucleus, the mitochondria, and the cell membrane in addition to changes in the cytoplasmic contents. There were also irregularities in the cell membrane. The most striking ultrastructure change was the presence of a large number of acidocalcisomes in the cytoplasm, which is important evidence of apoptosis (53). Only the promastigotes that were treated with lopinavir/ritonavir showed autophagy in addition to apoptosis. The increased number of vesicles with different densities in the cytoplasm, the rupture of the nuclear envelope, and the presence of dense chromatic granules are signs of autophagy $(24,54)$. The two major forms of programmed cell death, apoptosis and autophagy, were also verified in the ultrastructure study of $L$. amazonensis treated by HIV protease inhibitors (24).

In conclusion, administering drug combinations is more effective than that of individual drugs. Drug combinations of two compounds led to additive interactions. Furthermore, those of the three compounds showed synergistic activity. Synergism with this drug combination elicits a structure-function approach in fighting leishmaniasis. The electron microscopic study revealed that the three drugs exerted their anti-leishmanial action by inducing apoptosis, as well as autophagy in the case of lopinavir/ritonavir. The effectivity of this drug combination may be attributed to the similar mechanisms of action of its compounds. However, further experimental studies to establish the curative combination ratio and toxicity parameters of these compounds are needed, as well as others to test drug effectivity on amastigotes.

\section{References}

1. WHO Expert Committee on the Control of the Leishmaniases and World Health Organization. Control of the leishmaniases: Report of a meeting of the WHO Expert Committee on the Control of Leishmaniases, Geneva, 22-26 March, 2010. Geneva: World Health Organization; 2010. 
2. Alvar J, Vélez ID, Bern C, Herrero M, Desjeux P, Cano J, et al. Leishmaniasis worldwide and global estimates of its incidence. PLoS One. 2012;7:e35671.

https://doi.org/10.1371/journal.pone.0035671

3. Abou-El-Naga IF. Demographic, socioeconomic and environmental changes affecting the circulation of neglected tropical diseases in Egypt. Asian Pac J Trop Med. 2015;8:881-8. https://doi.org/10.1016/j.apjtm.2015.10.015

4. Zijlstra EE. PKDL and other dermal lesions in HIV co-infected patients with Leishmaniasis: Review of clinical presentation in relation to immune responses. PLoS Negl Trop Dis. 2014;20:8:e3258. https://doi.org/10.1371/journal.pntd.0003258

5. Grogl M, Hickman M, Ellis W, Hudson T, Lazo JS, Sharlow ER, et al. Drug discovery algorithm for cutaneous leishmaniasis. Am J Trop Med Hyg. 2013;88:216-21. https://doi.org/10.4269/ajtmh.11-0812

6. Amato VS, Tuon FF, Bacha HA, Neto VA, Nicodemo AC. Mucosal leishmaniasis. Current scenario and prospects for treatment. Acta Trop. 2008;105:1-9. https://doi.org/10.1016/j.actatropica.2007.08.003

7. Singh N, Kumar M, Singh RK. Leishmaniasis: Current status of available drugs and new potential drug targets. Asian Pac J Trop Med. 2012;5:485-97. https://doi.org/10.1016/S1995-7645(12)60084-4

8. Ekins S, Williams AJ. Finding promiscuous old drugs for new uses. Pharm Res. 2011;28:1785-91. https://doi.org/10.1007/s11095-011-0486-6

9. Planer JD, Hulverson MA, Arif JA, Ranade RM, Don R, Buckner FS. Synergy testing of FDAapproved drugs identifies potent drug combinations against Trypanosoma cruzi. PLoS Negl Trop Dis. 2014;8:e2977. https://doi.org/10.1371/journal.pntd.0002977

10. Das P, Alam MN, Paik D, Karmakar K, De T, Chakraborti T. Protease inhibitors in potential drug development for leishmaniasis. Indian J Biochem Biophys. 2013;50:363-76.

11. Saha AK, Mukherjee $\mathrm{T}_{\perp}$ Bhaduri A. Mechanism of action of amphotericin $\mathrm{B}$ on Leishmania donovani promastigotes. Mol Biochem Parasitol. 1986;19:195-200. https://doi.org/10.1016/0166-6851(86)90001-0

12. Alvar J, Croft S, Olliaro P. Chemotherapy in the treatment and control of leishmaniasis. Adv Parasitol. 2006;61:223-74. https://doi.org/10.1016/S0065-308X(05)61006-8

13. Rigobello MP, Scutari G, Boscolo R, Bindoli A. Induction of mitochondrial permeability transition by auranofin, a gold(I)-phosphine derivative. Br J Pharmacol. 2002;136:1162-8. https://doi.org/10.1038/sj.bjp.0704823

14. Ilari A, Baiocco P, Messori L, Fiorillo A, Boffi A, Gramiccia M, et al. A gold-containing drug against parasitic polyamine metabolism: The $\mathrm{X}$-ray structure of trypanothione reductase from Leishmania infantum in complex with auranofin reveals a dual mechanism of enzyme inhibition. Amino Acids. 2012;42:803-11. https://doi.org/10.1007/s00726-011-0997-9

15. Chandwani A, Shuter J. Lopinavir/ritonavir in the treatment of HIV-1 infection: a review. Ther Clin Risk Manag. 2008;4:1023-33. https://doi.org/10.2147/TCRM.S3285

16. Cvetkovic RS, Goa KL. Lopinavir/ritonavir: a review of its use in the management of HIV infection. Drugs. 2003;63:769-802. https://doi.org/10.2165/00003495-200363080-00004

17. Klemba M, Goldberg DE. Characterization of plasmepsin V, a membrane-bound aspartic protease homolog in the endoplasmic reticulum of Plasmodium falciparum. Mol Biochem Parasitol. 2005;143:183-91. https://doi.org/10.1016/j.molbiopara.2005.05.015

18. Derouin F, Santillana-Hayat M. Anti-Toxoplasma activities drugs and interactions with pyrimethamine and sulfadiazine in vitro. Antimicrob Agents Chemother. 2000;44:2575-7. https://doi.org/10.1128/AAC.44.9.2575-2577.2000

19. Parikh S, Gut J, Istvan E, Goldberg DE, Havlir DV, Rosenthal PJ. Antimalarial activity of human immunodeficiency virus type 1. Antimicrob Agents Chemother. 2005;49:2983-5. https://doi.org/10.1128/AAC.49.7.2983-2985.2005

20. Savoia D, Allice T, Tovo PA. Anti-leishmanial activity of HIV protease inhibitors. Int J Antimicrob Agents. 2005;26:92-4. https://doi.org/10.1016/j.ijantimicag.2005.04.003

21. Santos LO, Vitório BS, Branquinha MH, Pedroso e Silva CM, Santos AL, d'Avila-Levy CM. Nelfinavir is effective in inhibiting the multiplication and aspartic peptidase activity of Leishmania species, including strains obtained from HIV-positive patients. J Antimicrob Chemother. 2013;68:348-53. https://doi.org/10.1093/jac/dks410 
22. Pozio E. Highly active antiretroviral therapy and opportunistic protozoan infections. Parassitologia. 2004;46:83-9.

23. Trudel N, Garg R, Messier N, Sundar S, Ouellette M, Tremblay MJ. Intracellular survival of Leishmania species that cause visceral leishmaniasis is significantly reduced by HIV-1 protease inhibitors. J Infect Dis. 2008;198:1292-9. https://doi.org/10.1086/592280

24. Santos LO, Marinho FA, Altoé EF, Vitório BS, Alves CR, Britto C, et al. HIV aspartyl peptidase inhibitors interfere with cellular proliferation, ultrastructure and macrophage infection of Leishmania amazonensis. PLoS One. 2009;4:e4918. https://doi.org/10.1371/journal.pone.0004918

25. Demarchi IG, Silveira TG, Ferreira IC, Lonardoni MV. Effect of HIV protease inhibitors on New World Leishmania. Parasitol Int. 2012;61:538-44. https://doi.org/10.1016/i.parint.2012.04.006

26. Sanderson L, Yardley V, Croft SL. Activity of anti-cancer protein kinase inhibitors against Leishmania spp. J Antimicrob Chemother. 2014;69:1888-91. https://doi.org/10.1093/jac/dku069

27. Cleghorn LA, Woodland A, Collie IT, Torrie LS, Norcross N, Luksch T, et al. Identification of inhibitors of the Leishmania cdc2-related protein kinase CRK3. Chem Med Chem. 2011;6:2214-24. https://doi.org/10.1002/cmdc.201100344

28. Karaman MW, Herrgard S, Treiber DK, Gallant P, Atteridge CE, Campbell BT, et al. A quantitative analysis of kinase inhibitor selectivity. Nat Biotechnol. 2008;26:127-32. https://doi.org/10.1038/nbt1358

29. Goldberg DE, Siliciano RF, Jacobs WR. Outwitting evolution: Fighting drug-resistant TB, malaria, and HIV. Cell. 2012;148:1271-83. https://doi.org/10.1016/j.cell.2012.02.021

30. Ménez C, Buyse M, Besnard M. Interaction between miltefosine and amphotericin B: Consequences for their activities towards intestinal epithelial cells and Leishmania donovani promastigotes in vitro. Antimicrob Agents Chemother. 2006;50:3793-800. https://doi.org/10.1128/AAC.00837-06

31. Seifert K, Munday J, Syeda T. In vitro interactions between sitamaquine and amphotericin $\mathrm{B}$, sodium stibogluconate, miltefosine, paromomycin and pentamidine against Leishmania donovani. J Antimicrob Chemother. 2011;66:850-4. https://doi.org/10.1093/jac/dkq542

32. de Morais-Teixeira E, Gallupo MK, Rodrigues LF, Romanha AJ, Rabello A. In vitro interaction between paromomycin sulphate and four drugs with leishmanicidal activity against three New World Leishmania species. J Antimicrob Chemother. 2014;69:150-4. https://doi.org/10.1093/jac/dkt318

33. Barrett MP, Croft SL. Management of trypanosomiasis and leishmaniasis. Br Med Bull. 2012;104:175-96. https://doi.org/10.1093/bmb/lds031

34. McCartry-Burke C, Bates PA, Dwyer DM. Leishmania donovani: Use of two different commercially available chemically defined media for the continuous in vitro cultivation of promastigotes. Exp Parasitol. 1991;73:385-7. https://doi.org/10.1016/0014-4894(91)90112-A

35. Garcia LS. Parasite recovery: Culture methods, animal inoculation and xenodiagnosis. In: García LS, editor. Diagnostic Medical Parasitology. 5th edition. Washington, USA: American Society for Microbiology; 2007. p. 927-8.

36. Fivelman QL, Adagu IS, Warhurst DC. Modified fixed-ratio isobologram method for studying in vitro interactions between atovaquone and proguanil or dihydroartemisinin against drugresistant strains of Plasmodium falciparum. Antimicrob Agents Chemother. 2004;48:4097102. https://doi.org/10.1128/AAC.48.11.4097-4102.2004

37. Klainer AS, Betsch CJ. Scanning-beam electron microscopy of selected microorganisms. J Infect Dis. 1970;121:339-43. https://doi.org/10.1093/infdis/121.3.339

38. Bozzola JJ. Conventional specimen preparation techniques for transmission electron microscopy of cultured cells. Methods Mol Biol. 2007;369:1-18. https://doi.org/10.1007/978-1-59745-294-6 1

39. Chan YH. Biostatistics 102: Quantitative data- parametric \& non-parametric tests. Singapore Med J. 2003;44:391-6.

40. Siqueira-Neto JL, Song OR, Oh H, Sohn JH, Yang G, Nam J, et al. Anti-leishmanial highthroughput drug screening reveals drug candidates with new scaffolds. PLoS Negl Trop Dis. 2010;4:e675. https://doi.org/10.1371/journal.pntd.0000675

41. Gazanion E, Vergnes B, Seveno M. In vitro activity of nicotinamide/anti-leishmanial drug combinations. Parasitol Int. 2011;60:19-24. https://doi.org/10.1016/j.parint.2010.09.005 
42. Crowther GJ, Shanmugam D, Carmona SJ, Doyle MA, Hertz-Fowler C, Berriman M, et al. Identification of attractive drug targets in neglected-disease pathogens using an in silico approach. PLoS NegI Trop Dis. 2010;4:e804. https://doi.org/10.1371/journal.pntd.0000804

43. Valdivieso E, Dagger F, Rascon A. Leishmania mexicana: Identification and characterization of an aspartyl proteinase activity. Exp Parasitol. 2007;116:77-82. https://doi.org/10.1016/i.exppara.2006.10.006

44. Alves ÉA, de Miranda MG, Borges TK, Magalhães KG, Muniz-Junqueira MI. Anti-HIV drugs, lopinavir/ritonavir and atazanavir, modulate innate immune response triggered by Leishmania in macrophages: The role of NF-KB and PPAR-y. Int Immunopharmacol. 2015;24:314-24. https://doi.org/10.1016/j.intimp

45. Yu H, Guo P, Xie X, Wang Y, Chen G. Ferroptosis, a new form of cell death, and its relationships with tumourous diseases. J Cell Mol Med. 2017;21:648-57. https://doi.org/10.1111/jcmm.13008

46. Mesquita JT, Tempone AG, Reimão JQ. Combination therapy with nitazoxanide and amphotericin $\mathrm{B}$, glucantime, miltefosine and sitamaquine against Leishmania infantum intracellular amastigotes. Acta Trop. 2014;130:112-6. https://doi.org/10.1016/..actatropica.2013.11.003

47. Butcher EC. Can cell systems biology rescue drug discovery? Nat Rev Drug Discov. 2005;4:461-7. https://doi.org/10.1038/nrd1754

48. Lewis MG, Da Fonseca S, Chomont N, Palamara AT, Tardugno M, Mai A, et al. Gold drug auranofin restricts the viral reservoir in the monkey AIDS model and induces containment of viral load following ART suspension. AIDS. 2011;25:1347-56.

https://doi.org/10.1097/QAD.0b013e328347bd77

49. Croft SL, Sundar S, Fairlamb AH. Drug resistance in leishmaniasis. Clin Microbiol Rev. 2006;19:111-26. https://doi.org/10.1128/CMR.19.1.111-126.2006

50. Olliaro PL. Drug combinations for visceral leishmaniasis. Curr Opin Infect Dis. 2010;23:595602. https://doi.org/10.1097/QC0.0b013e32833fca9d

51. Borisy AA, Elliott PJ, Hurst NW, Lee MS, Lehar J, Price ER, et al. Systematic discovery of multicomponent therapeutics. Proc Natl Acad Sci USA. 2003;100:7977-82. https://doi.org/10.1073/pnas.1337088100

52. Sharlow ER, Leimgruber S, Murray S, Lira A, Sciotti RJ, Hickman M, et al. Auranofin is an apoptosis-simulating agent with in vitro and in vivo anti-leishmanial activity. ACS Chem Biol. 2014;21:663-72. https://doi.org/10.1021/cb400800q

53. González-Polo RA, Boya P, Pauleau AL, Jalil A, Larochette N, Souquère S, et al. Apoptosis/autophagy paradox: autophagic vacuolization before apoptotic death. J Cell Sci. 2005;118:3091-102. https://doi.org/10.1242/jcs.02447

54. Edinger AL, Thompson CB. Death by design: apoptosis, necrosis and autophagy. Curr Opin Cell Biol. 2004;16:663-9. https://doi.org/10.1016/j.ceb.2004.09.011 